\title{
CARACTERÍSTICAS
}

\section{SENSO-PERCEPTIVAS DEL SONIDO 5.1 EN LA COMUNICACIÓN RADIOFÓNICA}

\author{
Manuel Sánchez Cid - Universidad Rey Juan Carlos * \\ Anto Benítez - Universidad Carlos III* \\ *(APCS) Asociación por la Cultura del Sonido
}

\section{Resumen}

La tecnología de sonido envolvente 5.1 está en pleno desarrollo y experimentación. Discutiendo algunas de las principales características de la percepción desde los niveles más básicos de la comunicación sonora, el presente artículo aborda las ventajas que este sistema está en disposición de añadir a la radio actual.

El uso del sonido envolvente 5.1 moviliza la participación de los individuos receptores en el mensaje a partir de su mejor tratamiento de la forma sonora. Se remarcan los factores perceptivos que intervienen en este proceso.

\section{Palabras clave}

Comunicación Sonora; Radio; Espacio Sonoro; Sonido envolvente 5.1 
Manuel Sánchez Cid \& Anto Benítez: Características s senso-perceptivas del sonido 5.1 en la Comunicación Radiofónica.

\begin{abstract}
The technology of surround sound 5.1 is in full development and experimentation. Discussing some of the main characteristics of the perception process from the basic level of the sound communication, the present article looks for the advantages this system is making available to the actual radio broadcasting.

Using Surround Sound 5.1 can move individual in audience take part in message, improving its sound forms. Perception factors taking part in that process are shown.
\end{abstract}

\title{
Key Words
}

Sound Communication; Broadcasting; Spatial Audio; Surround Sound 5.1 


\section{Introducción}

Los medios de comunicación han intentado mediante los diferentes avances tecnológicos, crear, reconstruir o imitar la sensación de un entorno sonoro natural o, al menos, la estimulación, excitación y sensación que éste consigue en el ser humano. La búsqueda narrativa que comprende la recreación de sensaciones espaciales próximas a la realidad es, sin lugar a dudas, uno de los principales objetivos de la tecnología del sonido envolvente.

La radio, por su escaso número de ataduras referenciales -al no estar sometido a un referente físico visual-, favorece una mayor libertad para estimular y excitar sensorialmente, consiguiendo con ello vínculos sinestésicos ${ }^{1}$ difícilmente igualables. Sin duda, es un medio que favorece la creación y evocación de personajes, objetos y escenarios al precisar la participación activa del individuo receptor, lo que la sitúa en una posición de privilegio para la excitación sensorial a través de sus contenidos. Sin embargo, la limitación espacial que imponen los estándares tecnológicos de emisión actuales -sistemas mono y estéreo-, la impiden conseguir una sensación de espacialidad comparable al entorno natural, lo que merma de forma notable la integración perceptiva del mensaje, ya que no es equiparable la artificiosa sensación producida por un mensaje sonoro construido con un sistema de representación espacial de eje frontal de 60 grados a la sensación producida por el mismo sonido pero recreado en un campo sonoro con carácter circundante de 360 grados. El éxito del mensaje radiofónico se ve influido tanto por los aspectos de la forma sonora como por el carácter emocional de los contenidos, de manera que una podría realzar o atenuar la acción de 
los otros. Así, es preciso estimular la imaginación del oyente, provocar un vínculo emocional con el mismo y, por supuesto, conseguir reforzar el factor memoria-recuerdo. No obstante, a pesar de asumir que es un medio ventajoso desde un punto de vista comunicativo por su extraordinaria capacidad para movilizar la imaginación, una gran mayoría de los creativos y comunicadores radiofónicos parecen priorizar la sensorialidad básicamente a través del texto, relegando e incluso olvidando la capacidad expresiva que ofrece el resto de los elementos sonoros $\mathrm{y}$, en especial, el propio tratamiento de la forma sonora, es decir, el valor añadido que hoy día puede aportar la tecnología.

Por otro lado, es necesario tener en cuenta que el número de hogares españoles preparados para transcodificar mensajes en deliberada construcción espacial envolvente mediante sistemas home cinema, alcanza ya un $12 \%^{2}$, cifra que aumenta progresivamente año a año. Si embargo, podría objetarse que un determinado porcentaje de la audiencia radiofónica realiza una escucha de carácter dinámico, es decir, que no respeta la ubicación o ubicaciones estancas que requiere un sistema sonoro de reproducción espacial envolvente, dificultando así el alcance de la recreación de un espacio de escucha adecuado. Según nos muestra la propia historia de los medios audiovisuales, objeciones y dificultades como éstas nunca han constituido un obstáculo insalvable para que las mejoras tecnológicas de alcance profundo se desarrollasen, promoviendo la implantación de nuevos códigos que mejoran las posibilidades narrativas y la capacidad de penetración de los mensajes en la audiencia, como ejemplo, el paso del sistema mono al estéreo.

\footnotetext{
${ }^{1}$ En relación a la capacidad de estimular e interrelacionar unos sentidos a través de otros.

${ }^{2}$ Información extraída de la XII oleada del estudio: "Las TIC en los hogares españoles", Diciembre 2006.

Ministerio de Industria. http://observatorio.red.es/estudio/consumo/index.html
} 
Por tanto, el objetivo principal del presente artículo es resaltar que la producción radiofónica con sonido 5.1 consigue un mayor impacto sensorial, siendo claramente capaz de lograr una mayor eficacia comunicativa frente a los sistemas mono y estéreo. Para ello, profundizaremos en algunos los aspectos más significativos del proceso sensorial.

\section{Proceso senso-perceptivo en los mensajes}

\section{radiofónicos}

Existen divergentes opiniones en lo tocante a la importancia otorgada a la sensación respecto a la percepción en los procesos que pudiesen implicar a la audiencia radiofónica. Nos vemos obligados en este caso a establecer una mínima explicación aclaratoria que venga a defender la sustancial impronta que la comunicación sonora mediante tecnología envolvente aporta a los mensajes radiofónicos en el sustrato más básico o esencial de la comunicación.

Iremos viendo a continuación cómo el sonido 5.1 es capaz de comunicar eficazmente en ausencia de cualquier intervención de valores añadidos aportados por el intelecto (percepción); resultado de la respuesta positiva generada por la sensación a la intencionalidad del emisor del mensaje -comunicación basada en la relación acción-reacción-. Dicho proceso, valorable en toda estructura comunicativa, en absoluto desdeña la consiguiente carga de profundidad manejable en el proceso perceptivo puro, en el que las valoraciones personales intrínsecas a cada individuo le conceden al mensaje 5.1 otro valor añadido sumatoriamente efectivo. 
Para adentrarse en la explicación del proceso, por lo tanto, será necesario enumerar algunos de los aspectos esenciales de la secuencia perceptiva de los mensajes radiofónicos -aunque funcionen igualmente para todos los mensajes sonoros-, la cual viene definida por tres fases: la estimulación, la excitación y la sensación. En todos ellos se establecerá de forma oportuna la significativa relevancia que adquiere el sonido envolvente 5.1 por sus especiales características sensoriales.

\subsection{La estimulación}

Los receptores sensoriales son los encargados de captar los estímulos, transmitiéndolos casi simultáneamente al cerebro, donde se transforman en sensaciones. Cuando una persona carece de alguno de los sentidos, se ve privada de las sensaciones correspondientes y sus percepciones resultan perturbadas. Para que exista una sensación son necesarios tanto los estímulos como el procesamiento cerebral primario de los mismos. La estimulación de nuestros órganos sensoriales auditivos viene dada por la relación que el individuo mantiene con su medio. Huelga aclarar que la totalidad de los distintos entornos sonoros poseen características sonoras envolventes, que a su vez son captados por el ser humano desde su cualidad de escucha omnidireccional o de $360^{\circ}$. Contrariamente a lo que algunas personas puedan pensar, el hecho de que el sistema auditivo humano se componga de dos pabellones externos para la captación no se corresponde con una recepción estereofónica, sino que permite la audición y localización de todo sonido generado en un entorno tridimensional de $360^{\circ}$. Por tanto, cuando se construyen mensajes radiofónicos en los sistemas mono o estéreo, debido a su limitación de representación espacial, se hace imposible presentar los mensajes en 
el concepto omniespacial que nuestro sistema sensorial auditivo permite captar. Esta es una de las principales ventajas del sonido envolvente 5.1: la posibilidad de construir una estimulación espacial sonora sin limitaciones direccionales y, por lo tanto, semejante al oído humano sano. Muy pronto se podrá hablar de una reproducción sonora que albergue variables como la verticalidad y corporeidad del $\operatorname{sonido}^{3}$, lo que significaría obtener un avance tecnológico casi definitivo en el proceso de la estimulación auditiva.

\subsection{La excitación}

Toda excitación sensorial o fisiológica supone una alteración física de sus órganos receptores. Los estímulos que llegan a excitar los órganos auditivos obtienen una respuesta automática a nivel fisiológico: las contracciones y dilataciones del tímpano, la transmisión a través de la cadena de huesecillos del oído medio y el posterior proceso generado en el oído interno que es dirigido al sistema nervioso central. Tras la estimulación, el órgano excitado recupera su estado precedente. La excitación es, pues, una modificación pasajera, seguida por un retorno al equilibrio anterior.

Sin restar la oportuna importancia al grado de excitación fisiológica de los órganos sensoriales auditivos, se debe admitir que no es posible asociar un nivel de excitación proporcional al de eficacia comunicativa. Efectivamente, el grado de excitación auditiva producido por el mensaje radiofónico no debería encontrar paralelismos en términos de una mayor o menor eficacia, pues ésta no depende del grado de intensidad en decibelios que

\footnotetext{
${ }^{3}$ Cuestión de la que se ocupa en la actualidad la Asociación por la Cultura del Sonido, formada por investigadores de la UCM, Carlos III y URJC, más la colaboración de organismos concernidos.
} 
aplica el estímulo, ya que un mensaje contenedor de diferentes variables de intensidad sonora puede situar perfectamente la carga significativa y emotiva principal en los pasajes de menor intensidad. Sí se puede decir que un estímulo de mayor intensidad provoca un mayor grado de excitación, para bien o para mal, pero esto no significa de ninguna de las maneras que por ello el mensaje sea más eficaz.

Comunicativamente, concebir la sobredimensión de la excitación sonora de un mensaje radiofónico como sinónimo de efectividad sólo evidencia un defectuoso proceso de normalización dinámica que desestabiliza la correcta emisión y recepción, además de poder ocasionar un probable rechazo por parte del receptor de la señal. Una estimulación basada en una excitación de alto contraste de forma permanente tampoco sería una fórmula que se pudiera establecer como algo definitivo. En el entorno cotidiano no se suelen dar de forma continuada sobrecargas de estímulos excitadores, ya que esto provocaría una enorme fatiga tanto auditiva como atencional, además de generar a la larga un efecto "costumbre" neutralizador de la atención. Las personas que están inmersas de forma constante en entornos sonoros con niveles de intensidad elevados -por ejemplo, militares realizando ejercicios tácticos, profesionales de la pirotecnia, vecinos próximos a aeropuertos, etc.- pierden con el tiempo el efecto "sorpresa" que semejantes sonidos ocasionan en un principio, llegando incluso a mostrar una actitud de cierta indiferencia a dichas estimulaciones de alto nivel, aunque no por ello se pierda la sensación de molestia. Por el contrario, dichas personas son capaces de mostrar una mayor propensión a recibir impulsos novedosos de un nivel de presión sonora mucho menor.

Son numerosos los efectos nocivos ocasionados en la salud por un tipo de estimulación 
basada en grandes niveles de excitación de forma constante: estrés, insomnio, varices, depresiones, sordera, etc. Como referencia se puede consultar la obra de Guski, R., El ruido ${ }^{4}$.

En nuestra opinión, construir los mensajes radiofónicos con niveles constantes de excitación muy elevados o utilizar golpes sonoros reiterativos con la única intención de prevalecer sobre el resto de los contenidos de la programación y así captar la atención del receptor, no sólo no tiene una eficacia muy limitada, sino que es plenamente contraproducente -lo que no significa desechar este tipo de aplicación de forma puntual por necesidad estricta de la narración-. Parece más razonable asegurar que la atención se capta por un mensaje cuidado, y sobre todo, por la originalidad, ya sea de contenido, de forma, o por ambas, mientras que el efecto de impacto sonoro constante provoca rutina y desconexión atencional. Además, sería interesante tener en cuenta que por norma general, la señal que sale por el control de continuidad en una emisión radiofónica suele ser limitada o comprimida, lo que a priori neutralizará prácticamente todo efecto sensacionalista buscado mediante un aumento del nivel de presión sonora, igualando en gran medida los niveles de salida de la emisión radiofónica. Por lo tanto, el verdadero efecto de llamada se conseguirá generalmente por la originalidad de los contenidos y por el tratamiento de la forma sonora, pero no por la intensidad de la excitación medida en dB como prioridad. En este sentido, el sonido 5.1 ofrece una diferencia crucial frente a los formatos mono y estéreo: su capacidad para distribuir los estímulos tanto de forma interna como externa al campo de escucha, lo que posibilita un mayor abanico de puntos de emisión permitiendo una distribución más compensada de los niveles de excitación de cada uno de los puntos del campo sonoro.

\footnotetext{
${ }^{4}$ GUSKI, R. (1987), Wirkungen unerwünschter Geräusche, Berna, Verlag Hans Huber, 1987, (Edc. Esp. El
} 
Manuel Sánchez Cid \& Anto Benítez: Características s senso-perceptivas del sonido 5.1 en la Comunicación Radiofónica.

ICONO $14 \mathrm{~N}^{\circ} 9$ Junio 2007

Un ejemplo de aplicación podría ser una historia construida con sonido envolvente 5.1 donde el oyente estuviese en el punto central del campo de escucha y los acontecimientos se desarrollaran a su alrededor. Por ejemplo, el escenario es un campo de batalla y el oyente está inmerso en el mismo. En distintos puntos a su alrededor se escuchan constantes explosiones con gran nivel de presión sonora mientras que, al cabo de un rato, se puede escuchar un hilo de voz perteneciente a alguien gravemente herido que pide auxilio y lo hace con una expresividad absolutamente desgarradora. La pregunta aquí es: ¿qué sonido llamaría más la atención: el reiterativo de las explosiones sobrecogedoras, o la petición de ayuda? Si la respuesta -que parece de puro sentido común-, fuese la petición de ayuda, entonces podríamos enunciar que, más que el impacto de una fuerte intensidad de la señal, influye el tratamiento narrativo del contenido y de la forma.

La estimulación con 5.1 posibilita una excitación más promediada, inteligible y clarificadora por la menor concentración de estímulos; o dicho de otro modo, por su mayor capacidad de distribución espacial de las fuentes. Implícitamente, por tanto, la cobertura de estímulos lograda por un mensaje construido en 5.1 consigue una excitación más completa y precisa, consecuencia directa de la distribución de puntos focalizadores de la acción.

\subsection{La sensación}

Ruido, Efectos de los Sonidos no deseados, Barcelona, HERDER, 1989).

ICONO 14 - N 9 | REVISTA DECOMUNICACIÓN Y NUEVAS TECNOLOGÍAS | ISSN:1697 - 8293 
Según el Dr. Del Barrio ${ }^{5}$, sensación es la impresión producida por la acción directa de los estímulos sobre los órganos de los sentidos o, también, cualquier impresión de tipo interno, sentimiento o afecto.

Según Moliné: "los psicólogos consideran a las sensaciones como impresiones anteperceptivas de potencial emotivo con influencia en el ánimo, negando la posibilidad de una sensación desconectada de toda impresión” (Moliné, 1996: 209). Johannes Müller (1826), proporcionó un fundamento biológico a la tesis de la subjetividad de los sentidos, demostrando que un mismo estímulo aplicado a varios receptores originaba sensaciones distintas (en Pinillos, 1999: 110). Para Guski, no existe diferencia entre sensación y percepción; las observa como una realidad integrada (Guski, 1989: 212-215).

Es cuestión principal definir si las sensaciones poseen o no una cualidad interpretativa. Admitamos a partir de aquí, como indica Moliné, que la sensación es un proceso puro anteperceptivo completamente independiente de la valoración posterior que del mensaje pueda formalizar el receptor. Sin duda, la sensación generada en el receptor del estímulo poseerá distintos niveles de intensidad, lo que sugeriría que la sensación puede estar influida en cierto modo por las circunstancias personales de cada individuo. Si las reacciones obtenidas en los receptores correspondiesen al plan intencional buscado por quienes preparan y lanzan los estímulos, entonces se podría colegir que la sensación pertenecería en mayor proporción a aspectos relacionados con lo irracional ya que distintos individuos, a igualdad de estímulos, producen reacciones semejantes.

En opinión de Pinillos:

\footnotetext{
5 Dr. Rodríguez del Barrio, neurocientífico del Hospital Ramón y Cajal de Madrid. Entrevista realizada por los
} 
El origen de los instintos, las emociones, las pasiones y otras manifestaciones irracionales, derivan de la sensación. La percepción siempre es valorada con un carácter más totalizador, más racional, mientras que la sensación es asociada a un proceso de carácter más pasivo, más irracional (Pinillos, 1999: 147-148).

Sin duda, éste es uno de los puntos importantes a tener en cuenta en la construcción de todo mensaje radiofónico: el peso específico de las sensaciones como reacción espontánea directa sin la mediación de otras valoraciones añadidas. Es más, de cara a las necesidades del comunicador radiofónico podría plantearse la siguiente pregunta: ¿qué puede ser más productivo para los intereses del comunicador, activar la sensación o la percepción? Por lo visto hasta ahora, ésta última es mucho más subjetiva, pues influyen numerosos parámetros relacionados con la experiencia y bagaje de cada persona, cuestión que deja abierta la reacción del receptor.

En opinión compartida con estudiosos del tema, la sensación tiene mucho que ver con las emociones, siendo éstas un factor decisivo en la pregnancia del mensaje sonoro.

1.3.1 Las emociones. Para el Dr. Magariños ${ }^{6}$, la emoción puede entenderse como una reacción afectiva inducida de carácter intenso, siendo capaz de arrebatar temporalmente el dominio a la razón, por eso, a nuestro entender, todo mensaje con una carga emocional eficaz puede saltarse las barreras de protección que establece lo racional. No obstante, la emoción no debe buscarse aleatoriamente, pues podría resultar contraria al deseo inicial del emisor.

autores en Junio de 2005. No publicada.

${ }^{6}$ Dr. Magariños, C., neurocientífico del Hospital Ramón y Cajal de Madrid. Entrevista realizada por los autores en Junio de 2005. No publicada. 
Existe una tendencia a pensar que al actuar más sobre la emoción que sobre la razón se consigue conmover más que convencer, como Hollingworth, quien asocia la idea de impresionar con la de conmover (en Ross, 1978: 212). Aunque la observación tiene su lógica, porque las emociones son asociables a reacciones afectivas, no debería poder asumirse en su totalidad, pues no todas las emociones son de carácter conmovedor. Además, si consideramos nuestra propia experiencia cotidiana, creemos necesario resaltar su importancia en los procesos de aprehensión de los mensajes, ya que las emociones pueden perdurar en el tiempo en ausencia del estímulo o reacción orgánica, pueden intervenir de manera decisiva en los procesos de memorización y adquisición del conocimiento, y colaboran en la toma de decisiones. Por tanto, es lógico deducir que todo mensaje poseedor de una carga emocional sólida que logre una sensación de vínculo afectivo, pero sin perder la apariencia racional, encontrará menos barreras para lograr sus objetivos comunicativos. No se debería pasar por alto la asociación afectiva innata como acto reflejo del proceso cognitivo, es decir, aquella que se genera sin necesidad de aplicar significados al acontecimiento.

La variedad de datos contenidos en todo paisaje sonoro es una fuente generadora de impresiones complementarias y todos los datos adyacentes o complementarios son valorados en el proceso cognitivo. Por esto, la señal radiofónica con sonido envolvente 5.1 logrará una asociación interrelacional con los entornos naturales o paisajes sonoros originarios portadores de valores en sí mismos. Reacciones instantáneas anteperceptivas desprovistas de valoraciones añadidas a posteriori, con sensaciones y emociones reactantes producidas por la 
propia conexión establecida en interrelación con un entorno sólo reproducible y asociable en su más completa integridad por un sistema sonoro envolvente.

La posibilidad de trabajar con cinco puntos emisores no dependientes, otorga al comunicador el beneficio de una escena sonora menos concentrada espacialmente y, por tanto, con una variedad de instrumentación narrativa netamente superior a la ofrecida por los sistemas mono y estéreo.

\section{Percepción}

Se entiende por percepción "la toma de conciencia de la sensación, esto es, la aprehensión de la realidad a través de la información captada en el ambiente y registrada por los sentidos" (Sánchez, Franco, 1999: 27-40). También, el "proceso sensocognitivo en el que las cosas se hacen manifiestas como tales en un acto de experiencia. (...) Percibir entraña un cierto saber acerca de las cosas percibidas y sus relaciones" (Pinillos, 1999: 153).

No cabe duda que la percepción es un proceso en el que están implicados procesos cognitivos tales como la memoria y el pensamiento; por tanto, se podría hablar también de recepción, comprensión y asimilación del mensaje.

En resumen, se puede decir que la percepción es un proceso psicofísico por el que el sujeto transforma las diversas impresiones sensoriales en objeto sensible conocido. Conlleva un proceso de cuatro cambios sucesivos que van de una reacción más directa a una más elaborada: la estimulación sensorial, la excitación de los órganos sensores, la sensación o reacción emocional y el matiz que la diferencia de la sensación: la integración totalizadora de 
conocimientos. En nuestra opinión, cuando se percibe, al mismo tiempo que se recibe la información se participa activamente en dicha recepción, de tal manera dicha percepción es el resultado de lo comunicado por los sentidos y la contribución del sujeto perceptor. En este sentido, se podría decir que la percepción es una representación de la realidad en la cual el sujeto perceptor aporta su experiencia particular al proceso de comprensión y asimilación del mensaje, siendo este bagaje un requisito igualmente productivo de cara a las posibilidades que el sonido 5.1 ofrece en la construcción e interpretación del mensaje radiofónico. Es precisamente la experiencia acumulada en los distintos ambientes y entornos sonoros pertenecientes o no al ámbito de la realidad- lo que construye de forma progresiva un amplio abanico referencial. Las distintas realidades que el individuo ha experimentado, directa o indirectamente, a lo largo de su existencia formalizan un catálogo de situaciones y ambientes sonoros representativos. Por ello, un mensaje que pueda ser asociado o que directamente recree un aspecto de nuestra realidad cotidiana, tiene un mayor grado de identificación en el receptor y un mayor porcentaje de éxito en el proceso de llamada atencional. Con el sonido 5.1 el realismo es tal, que no sólo se dota al mensaje de un elevado nivel de credibilidad y estimulación sinestésica, sino que la recreación ambiental en el receptor queda intensamente relacionada con la propia definición creativa del mensaje, con lo que se da una menor cabida a posibles alteraciones de carácter significativo no controladas por el emisor, como podría suceder más a menudo en los sistemas mono o estéreo.

En opinión de Muscarsel, “cuando un individuo oyente que ha tenido un desarrollo normal escucha un sonido, tiende a asociarlo con el objeto que lo produjo basándose en experiencias anteriores" (Muscarsel, 1988: 69). 
El realismo sonoro que aporta la espacialidad del 5.1 se convierte en una experiencia capaz de ser almacenada como una realidad propia, extrapolable en el espacio y el tiempo, dotando al mensaje de una huella más duradera que los mensajes limitados espacialmente.

\subsection{Factores que influyen en la percepción}

Si consideramos que nuestras vivencias acontecen en distintos entornos sonoros con carácter omniespacial, podría decirse que todos los factores que influyen en nuestra percepción y que tienen alguna relación con las vivencias auditivas, harán referencia directa a entornos de sonido de carácter envolvente. En definitiva, las experiencias se desarrollan en ambientes y entornos sonoros en los que el individuo está naturalmente inmerso, siendo imposible encapsular cada uno de los sonidos que le rodean. Por ello, los recuerdos y experiencias deberían tener un nivel referencial más activo a través de los mensajes con ambientes omniespaciales -entre otros aspectos, por la mayor riqueza de detalles significativos-, lo que facilitaría netamente el proceso de asimilación, asociación y comprensión de los mensajes construidos con sonido 5.1.

Atendiendo a los aspectos anteriores, podemos decir que la percepción puede estar motivada por factores tanto internos como externos. De entre los numerosos factores influyentes en el proceso perceptivo clasificados por autores como Meldman (1970), Wittenborn (1943), Butler (1953) o Berline (1966), destacamos a continuación los factores que a nuestro entender influyen en mayor o menor grado en el proceso perceptivo de los mensajes radiofónicos. 
2.1.1 Factores personales o internos. Los factores personales son los que dependen de las características particulares de cada individuo y los más destacables son:

\section{- La atención}

Siempre haciendo referencia al proceso de percepción sonora, se entiende que la atención puede ser un ejercicio tanto voluntario como involuntario; es decir, aunque ésta tiene mucho que ver con la intencionalidad del individuo, en numerosas ocasiones llama la atención un sonido que en absoluto se ha decidido percibir. En este sentido, mucho tiene que ver la variopinta oferta sonora que rodea constantemente al individuo en su medio natural. Es tal la variedad de estímulos sonoros que el ser humano realiza un ejercicio de selección sin considerar que gran parte del resto de los estímulos también son percibidos, aglutinados y compactados junto a la selección principal. Ante la complejidad que supondría percibir absolutamente todos los sonidos circundantes de forma simultánea en un mismo orden de prioridad, la atención posibilita al receptor elegir la información que entiende prioritaria en cada instante respecto a la totalidad de sonidos que le llegan. Este ejercicio de discriminación sonora no significa que el resto de informaciones no seleccionadas como principales se pierdan o no tengan importancia; en absoluto, es justamente esta información adyacente y complementaria la que otorga credibilidad al mensaje y colabora en la gestión integradora del proceso perceptivo. Es más, este conjunto de sonidos es el que va a permitir identificar, asociar y reconstruir fragmentos sonoros parciales. 
A nuestro juicio, el mensaje sonoro radiofónico construido en sistema 5.1 capta en mayor medida la atención del receptor por su capacidad de recrear en un campo de escucha artificial limitado un entorno natural, y evitar así distracciones al mostrarse más impermeable a sonidos externos ajenos al mensaje. Por el contrario, el mensaje mono o estéreo, al focalizar la acción en un campo sonoro parcial, se muestra más permeable a contenidos ajenos, provocando una menor integración perceptual y una mayor distracción. En igualdad de condiciones, será más factible captar la atención de la percepción radiofónica mediante un sistema dotado de una mayor capacidad asociativa y de una mayor capacidad de integración del receptor al ambiente cotidiano, que mediante uno que presente artificiosidad en lo relativo a la credibilidad espacial.

\section{- El interés}

Es lógico pensar que el ser humano, por lo general, se expone con una mayor predisposición a todo aquello que está de acuerdo o próximo a sus intereses, siendo influido a su vez por todo aquello que llama su atención. Indiscutiblemente todas nuestras vivencias son relacionables con un entorno en el que nace y se desarrolla nuestro interés por algo o alguien, por lo que cabría preguntarse si la ambientación realista que aporta el sonido envolvente 5.1 al mensaje podría ser asociada con los ambientes específicos existentes en los momentos en los que se establecen los intereses personales del receptor y que se ven reflejados en el proceso perceptivo. Entendemos que la respuesta sería de carácter afirmativo, fundamentándonos sencillamente en esa asociación innata y automática que va implícita a cada instante determinado en el que se marcan nuestros gustos, prioridades y preferencias. 
Desde la perspectiva del interés puramente estético, cuantificando las posibilidades dinámicas del proceso creativo desde el punto de vista matemático de la combinatoria, el número de posibles variaciones constructivas del mensaje sonoro mediante el modelo 5.1 es superior en grado máximo a las que ofrecen los sistemas mono y estéreo. Lo que puede interpretarse como un factor de alcance decisivo a la hora de captar y generar interés en el receptor del mensaje.

\section{- La afectividad}

Indiscutiblemente, los mensajes radiofónicos que conllevan una carga afectiva suelen establecer un vínculo emocional perdurable que se anticipa con solvencia a los filtros perceptivos. La relación afectiva del mensaje sonoro puede establecerse por la asociación a momentos o vivencias concretos, o por la reacción inherente en el ser humano derivada de la utilización de determinados ritmos, melodías, tonalidades, tesituras y ambientaciones complejas. Por lo general, existen determinados ambientes sonoros predefinidos por las distintas culturas, que son asociables a diferentes niveles de afectividad; ambientes que desde el punto de vista de la estimulación sensorial de nuestros sentidos, se generan en un entorno natural de carácter circundante o envolvente.

- La familiaridad

La familiaridad es un factor importante en la dinámica asociativa y perceptiva que pone en marcha el receptor en la interpretación del mensaje radiofónico con sonido 5.1. Se entiende que la auténtica familiaridad del código sonoro se lleva a cabo de forma natural y espontánea 


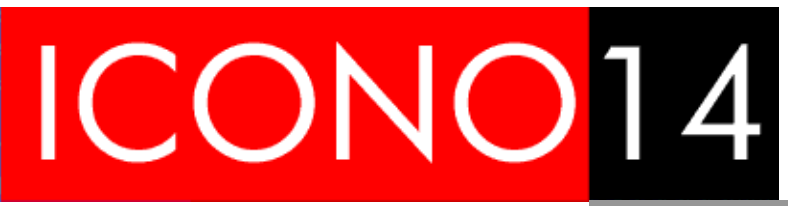

Manuel Sánchez Cid \& Anto Benítez: Características s senso-perceptivas del sonido 5.1 en la Comunicación Radiofónica.

ICONO 14 N $^{\circ} 9$ Junio 2007

cuando nuestro procesamiento mental no necesita ejecutar tareas complementarias para recrear la verosimilitud que el mensaje debería ofrecer por sí mismo. En consecuencia, mantener en el mensaje radiofónico el realismo o la apariencia de las sensaciones percibidas por el oyente en su entorno, favorece el reconocimiento y la familiaridad con el sonido que a diario se establece a nuestro alrededor.

- La memoria

Al hallarse la percepción plenamente interrelacionada con la memoria, el conocimiento perceptivo dependerá en gran medida del grado, la naturaleza y el valor de las experiencias pasadas. Es lógico pensar que, cuanta más precisión realista consigan los mensajes -como sucede con los construidos con sonido envolvente 5.1-, se asociarán con mayor facilidad a esquemas cognitivos fruto del aprendizaje anterior.

2.1.2 Factores externos. Son los que influyen en el sujeto desde el mundo exterior a él. A nuestro juicio los más significativos son:

- La intensidad del estímulo: 
Una vez más se insiste en que la intensidad no es un factor determinante a la hora de buscar la efectividad definitiva de un estímulo radiofónico; sin embargo, utilizada con orden y acierto, puede contribuir positivamente en el proceso perceptivo.

- La movilidad y las variaciones:

Los estímulos móviles facilitan la percepción frente a los que permanecen estáticos o invariables. Desde un punto de vista puramente sicoacústico, éste es un factor que marca diferencias insalvables entre el sonido envolvente $5.1 \mathrm{y}$ los sistemas mono y estéreo. El sonido envolvente 5.1 permite 360 ejes de acción externos y casi infinitas variaciones posicionales internas en su propio campo de escucha.

- La ubicación espacial:

Las personas son eje central de todas sus vivencias, por ello, su escucha siempre es punto de referencia orientativa y espacial respecto al entorno, aunque perceptivamente el individuo sea capaz de adaptarse a focalizaciones puntuales de la acción. Con el sistema 5.1 se rompe la dependencia estratégica del punto de escucha central del estereofónico para la correcta audición e interpretación de la narración del mensaje radiofónico. Gracias a su multiespacialidad, tanto el punto de escucha como la ubicación de los elementos componentes de un determinado mensaje pueden percibirse distribuidos tanto en el centro como en puntos alternativos del campo de escucha, permitiendo a su vez una mayor libertad en el posicionamiento perceptivo del receptor. Los conceptos de toma y reconstrucción centrípeta y 
centrífuga, como establecedoras de perspectivas de acción y de escucha, ponen de manifiesto dos características inviables en los sistemas mono y estéreo.

\section{Comprensión e integración del mensaje}

Según Schank, “comprender significa recordar la experiencia previa más parecida a los datos que se están recibiendo en ese momento" (Alonso, 2004: 86). La comprensión del mensaje radiofónico por tanto, requiere un cierto nivel de colaboración por parte del receptor para interpretar adecuadamente el discurso. Por su parte, el comunicador debe construir el mensaje con sencillez, ya que una complejidad y confusión innecesarias pueden obstaculizar la comprensión del mismo. Es necesario insistir en el aumento de las variables interpretativas que posibilita un entorno sonoro 5.1 capaz de reconstruir las experiencias o entornos cotidianos de forma semejante a como las percibe el receptor en su ámbito natural. La integración que el receptor puede hacer de un mensaje creíble en su máxima expresión significa un reconocimiento e identificación automático muy por encima del que ofrecen los sistemas no envolventes. Se hace referencia a fracciones de segundo; tiempo e información lo suficientemente significativos como para que el proceso de identificación active los mecanismos de reconocimiento e integración del mensaje y logre una familiarización automática con el mismo. De aquí se puede inducir que quien envía un mensaje radiofónico debe ordenar y elegir su material de modo que utilice en la mejor medida posible los presumibles conocimientos y experiencias de los receptores. El modo en que es recibido e interpretado el mensaje radiofónico influirá en la aceptación, rechazo, almacenamiento y 
posterior acción o conducta. En consecuencia, es lógico pensar que la comprensión e integración del mensaje estará sumamente relacionada con su credibilidad y con la forma en que se manejen las dimensiones pragmáticas.

En opinión de Ross, “el hombre tiende a comprender un mensaje y a sentirse afectado por él cuando le aplica sus conocimientos y experiencias previas” (Ross, 1978: 203).

Llegados a este punto, estamos en disposición de decir que facilitar la comprensión del mensaje radiofónico mediante los principios fundamentales de orden, coherencia, naturalidad ambiental, credibilidad y claridad conceptual, no sólo supone facilitar el aprendizaje, sino que va más allá: significa facilitar su integración y aceptación como realidad representativa, posibilitando una mayor proximidad y efecto recuerdo.

\section{Memoria auditiva}

Comprender como funciona la memoria auditiva humana ayuda a conseguir una de las claves del proceso comunicativo. Para ello es necesario observar los sonidos que nos rodean, ya sean palabra, música, efectos o silencio; todos están incluidos en un ambiente sonoro constante que cambia conforme cambia el propio paisaje sonoro. De aquí podría surgir la siguiente pregunta: ¿en alguna ocasión, al finalizar un día, se ha intentado recordar todos aquellos sonidos que, de forma consciente o inconsciente, se han ido percibiendo a lo largo del mismo? La respuesta casi con absoluta seguridad será de carácter negativo, exceptuando algún ejercicio deliberado. ¿Y qué se recuerda mejor, las palabras, las músicas, los efectos, el silencio, los sonidos ambientales, los que están en primer término, en segundo, los de mayor intensidad, los de menor, los que se dirigen a nosotros, los que se dirigen a alguien próximo, 
los que van dirigidos a alguien desconocido, los mensajes delicados, los agresivos, los alarmantes, los que nos afectan directamente, los que no nos interesan, los que nos obligan, los aleatorios, los cargados de sentimiento...? He aquí una serie de factores dignos de consideración. Lo cierto es que nuestra memoria auditiva es capaz de almacenar y gestionar datos referidos a tonalidades, texturas, intensidades, distancias, timbres, inflexiones, curvas melódicas, ritmos, datos referentes a espacios, movimientos, cualidades físicas, psíquicas, y un sin fin de variables igualmente importantes. Resulta llamativo observar que seamos capaces de identificar miles de ambientes sonoros específicos, cientos de timbres de voces e instrumentos musicales, sonidos propios de vehículos, de animales, etc. Como dato constatado, se destaca el hecho de que personas que tienen dificultades para memorizar un documento de dos páginas, sin embargo, son capaces de almacenar y recordar las letras de cientos de canciones. En definitiva, nuestra memoria auditiva es un enorme almacén gestionado por un sistema logístico altamente eficaz. A este respecto, Trout y Rivkin recogen una serie de investigaciones que confirman que la mente trabaja a través del oído y no de la vista: "en muchas formas, el oído es superior a la vista. Lo que se quiere decir es que existen estudios controlados en laboratorio que demuestran que cuando se presenta una lista de palabras a la gente, y dicha presentación se realiza auditiva y visualmente, la gente recuerda más las palabras si las oye que si las ve” (Trout y Rivkin, 1996: 93-95).

Según Rodríguez Bravo, en la memoria auditiva se van acumulando formas-patrón que constituyen un amplio muestrario que orientará nuestra manera de escuchar, organizar, seleccionar e interpretar las mezclas de sonido que provienen de nuestro entorno. Dicha capacidad memorística está sumamente relacionada con la experiencia individual de cada 
persona, ya que aquella facilitará notablemente los procesos de asociación y reconocimiento de las formas sonoras. No obstante, la asociación de los mensajes almacenados respecto a los nuevos estímulos será más efectiva si existe una cierta correspondencia estructural sonora. Esto es, de los tres formatos aquí mencionados: mono, estéreo o 5.1, éste último es el que verdaderamente consigue las relaciones espaciales que se dan en los ambientes sonoros reales, facilitando a sus mensajes tanto el almacenamiento como su recuperación.

Rodríguez Bravo entiende que:

en la memoria auditiva de cualquier persona está presente la experiencia de una asociación inmediata y lógica entre el alejamiento o acercamiento de las fuentes sonoras y la intensidad de los sonidos que emanan de ellas. También es habitual recordar la relación que existe entre los movimientos laterales de las fuentes sonoras y la sensación de direccionalidad del sonido, o la asociación entre el volumen del lugar donde se encuentra la fuente sonora y la sensación de reverberación (Rodríguez, 1998: 225).

En definitiva, la experiencia sonora de cualquier persona guarda una estrecha relación con ambientes captados por un tipo de escucha omnidireccional, lo que significa que el proceso de identificación y recuperación de los datos almacenados en la denominada memoria auditiva, reaccionará principalmente ante determinados estímulos por simple asociación o reconocimiento.

\section{El sonido 5.1 como motor del ejercicio}




\section{imaginativo}

De la percepción, pasando por la memoria, se llega a la imaginación. Según Costa (1992), transformamos percepciones e impresiones en representaciones mentales, por tanto, se puede decir que la imaginación es la facultad de la mente para producir y formar combinaciones originales de imágenes en la memoria, utilizando los recuerdos y experiencias del pasado. En otras palabras, es la facultad por la que una persona percibe los elementos del entorno virtual y los interpreta como reales. La imaginación, al igual que la memoria, ayuda a interpretar los estímulos que excitan los sentidos y generan la percepción.

Respecto a la capacidad imaginativa del ser humano, Luria (1980: 172) entiende que existen dos tipos de imaginación:

- imaginación reproductora: referida a la experiencia pasada,

- imaginación creativa: referida a procesos novedosos puramente creativos.

Se podría decir que la imaginación creativa mantiene un nexo con la realidad, con las experiencias vividas, siendo en cierto modo el punto de partida de muchos de los procesos de su construcción. A su vez, todo mensaje radiofónico debería lograr una cierta complicidad imaginativa por parte del receptor, pero como complemento controlado, ya que de lo contrario se corre el riesgo de perder la identificación deseada. Es decir, que se debería buscar una participación del receptor bien a nivel puramente cognitivo -activar la imaginación del receptor-, o bien a nivel implicativo -toma de contacto-. En sentido lógico, ha de existir proximidad entre la representación que del mensaje debe hacer el receptor y la pretendida por el comunicador, ya que cuanto mayor coincidencia se consiga, mayores serán las posibilidades de lograr una verdadera eficacia del mensaje. 
En relación a lo expuesto hasta el momento, cabe plantearse la siguiente pregunta: ¿consigue la comunicación radiofónica actual movilizar la imaginación del receptor? A nuestro juicio se evidencia en ella una cierta rutina que deriva en una falta de excitación multisensorial. Es limitada, reiterativa y muy plana. Deja bastante indiferente al receptor, sólo busca exponer su discurso y no ofrece un valor añadido a la recreación imaginativa. En buena medida, parte de la responsabilidad de esta ausencia de excitación de la imaginación se debe a la pobre instrumentación que del sonido se hace. Continuamente se articulan mensajes basados en la misma estructura -esto es perfectamente comprobable con un simple análisis cuantitativo-: una o varias voces principales de características tonales genéricas; una música a modo de fondo que la mayoría de las veces en poco ayuda al buen entendimiento y fijación de los valores pregnantes del mensaje; una serie de efectos utilizados siempre con carácter descriptivo y mucho, mucho texto. Parece que interesa más decirlo todo que activar la parte imaginativo del receptor. Por otro lado, tenemos el aspecto de la forma, el cómo envolver el contenido, cómo significar el mensaje mediante la estructura sonora. El sonido por sí mismo despierta la evocación y el reconocimiento de la realidad. No se debería olvidar que la realidad permite lo irreal, y gracias a un conocimiento de lo real se puede desarrollar lo imaginario. Alonso (2004: 155) entiende que el realismo del mensaje es vital para la gestión imaginativa del receptor:

el decorado sonoro que aparece en el mensaje y que se envía al oyente debe evocar el marco en que se desarrolla la acción a que se alude. No puede tratarse de un componente sonoro más, sino que debe estimular al sujeto receptor para 
que cree en su imaginación el decorado más eficaz y atractivo.

Esto es en esencia el sonido 5.1: una aproximación al realismo en estado puro, la posibilidad cierta de lo imaginativo en su máxima expresión.

\section{CONCLUSIONES}

- Desde el aspecto del proceso cognitivo, la comunicación radiofónica en sonido envolvente 5.1 posee un especial poder evocador al ser capaz de captar las sensaciones de los entornos sonoros utilizando el sonido ambiental como elemento de refuerzo expresivo. Los contenidos radiofónicos construidos con sonido 5.1, al proporcionar una mayor familiaridad con los ambientes, provocan un alto grado de identificación; de esta manera se facilita la estructuración del mensaje y por tanto la recuperación de la información.

- Al producirse una estimulación sonora de entorno global de alta precisión fuera de su entorno natural, se consigue un refuerzo automático en la impresión mental o huella que dicho mensaje provoca en el receptor. Por ello, una de las singulares características sensoriales del sonido 5.1, es su capacidad de ambientación inmersiva o globalizadora, que permite situar al receptor del mensaje como posible eje central de la acción, proporcionándole la impresión de que en torno a él se suceden todos los acontecimientos -circunstancia absolutamente inviable con los sistemas mono o estéreo-. Esto incide directamente en el proceso de captar la atención, logrando que 
mensajes que en otros sistemas pasarían desapercibidos despierten, con el 5.1, el interés gracias a la forma sonora.

- $\quad$ Permite una extraordinaria asociación multisensorial, por lo que consigue una mejor asociación con la experiencia acumulada en las distintas realidades de cada individuo, aumentando así la relación afectiva con el mensaje sonoro y logrando una mayor respuesta emocional. Facilita la consecución de sensaciones espaciales próximas a la realidad y una más completa relación sinestésica. Potencia la estimulación, la fantasía, la imaginación, facilita la memorización y la creación de imágenes visuales. Y por supuesto, gracias a su movilidad espacial, dota de gran credibilidad al mensaje consiguiendo un elevado realismo y una mayor intensidad expresiva.

- El mensaje radiofónico con sonido 5.1 invoca en mayor medida a la memoria auditiva profunda. El cerebro guarda todos los momentos sonoros de nuestras vidas, por lo que el sistema 5.1 es capaz de reconstruir las escenas y los recuerdos gracias a su mayor capacidad de lograr el contexto asociativo. Una de las principales cualidades innatas del sistema 5.1, es su capacidad para facilitar la comprensión y asimilación del mensaje.

Como consecuencia inmediata, desde un punto de vista puramente narrativo, el sistema 5.1 proporcionará:

- Un espacio sonoro de $360^{\circ}$, lo que permite generar escenarios inmersivos. 
- Múltiples ejes de acción y localizaciones.

- Acciones independientes y simultáneas desde cualquier punto del campo de escucha.

- Una perfecta recreación del espacio sonoro.

- La multiperspectiva. El 5.1 permite una casi perfecta construcción de la profundidad espacial y componer diferentes perspectivas sonoras.

- Variar el punto de escucha y por tanto, variar el protagonismo tanto de los actores de la narración como de los receptores de la misma. Esto posibilita una interdependencia plena entre a narración y la funcionalidad espacial de los receptores.

- Facilitar la estructuración del mensaje, su claridad, concreción y su mayor comprensión.

A lo largo del presente artículo, estimamos que se han expuesto razonamientos suficientemente válidos para considerar que los mensajes radiofónicos construidos con 5.1 son más identificables, asociables, creíbles y comprensibles, gracias a esa correspondencia con las experiencias sonoras personales de nuestra vida cotidiana. Además, existe la prueba empírica de que los estímulos sonoros reconstruidos y recreados de forma más realista facilitan el recuerdo, siendo más fácilmente recuperables que los de carácter más abstracto, los cuales resultan menos identificables. ${ }^{7}$

\footnotetext{
${ }^{7}$ Se remite al experimento de laboratorio realizado por Manuel Sánchez Cid en su tesis doctoral "La Capacidad Comunicativa del Sonido Envolvente 5.1 en la Producción Publicitaria Radiofónica en España” Cap. V., en el
} 


\section{BIBLIOGRAFÍA CITADA}

- ALONSO, 2004. El Canto de las Sirenas, Salamanca, Universidad Pontificia de Salamanca.

- COSTA, 1992. Imagen pública, Madrid, Fundesco.

- GUSKI, 1987. Wirkungen unerwünschter Geräusche, Berna, Verlag Hans Huber, (ed. esp. El Ruido, efectos de los sonidos no deseados, Barcelona, HERDER, 1989).

- LURIA, 1980. Los procesos cognitivos, Barcelona, Fontanella.

- MOLINÉ, 1996. La comunicación activa, publicidad sólida, Bilbao, Deusto.

- MUSCARSEL, 1988. El mundo sonoro, Madrid, CEPE.

- PINILLOS, 1999. Principios de Psicología, Madrid, Alianza Editorial.

- RODRÍGUEZ, 1998. La dimensión sonora del lenguaje audiovisual, Barcelona, Paidós.

- ROSS, 1974. Persuasion: Comunication and interpersonal Relations, New Jersey, Prentice-Hall, (ed. esp. Persuasión, México, Trillas, 1978).

- SÁNCHEZ CID, 2006. Capacidad Comunicativa del Sonido Envolvente 5.1 en la Producción Publicitaria Radiofónica en España. No editada.

- SÁNCHEZ FRANCO, 1999. Eficacia Publicitaria, Madrid, McGrawHill.

- TROUT, y RIVKIN, 1996. The new positioning, London, McGraw-Hill, (ed. esp. El nuevo posicionamiento, Madrid, McGraw-Hill, 1997).

- VERNON, 1973. The Psychology of Perception, Penguin Books, (ed. esp. Psicología de la Percepción, Buenos Aires, Paidós, 1973). 